\title{
Soil atmosphere exchange of carbonyl sulfide (COS) regulated by diffusivity depending on water-filled pore space
}

\author{
H. Van Diest and J. Kesselmeier \\ Max Planck Institute for Chemistry, Biogeochemistry Dept., Joh.-J.-Becher-Weg 27, 55128 Mainz, Germany \\ Received: 12 September 2007 - Published in Biogeosciences Discuss.: 12 October 2007 \\ Revised: 15 February 2008 - Accepted: 25 February 2008 - Published: 1 April 2008
}

\begin{abstract}
The exchange of carbonyl sulfide (COS) between soil and the atmosphere was investigated for three arable soils from Germany, China and Finland and one forest soil from Siberia for parameterization in the relation to ambient carbonyl sulfide (COS) concentration, soil water content (WC) and air temperature. All investigated soils acted as sinks for COS. A clear and distinct uptake optimum was found for the German, Chinese, Finnish and Siberian soils at $11.5 \%, 9 \%, 11.5 \%$, and $9 \%$ soil $\mathrm{WC}$, respectively, indicating that the soil WC acts as an important biological and physical parameter for characterizing the exchange of COS between soils and the atmosphere. Different optima of deposition velocities $\left(V_{d}\right)$ as observed for the Chinese, Finnish and Siberian boreal soil types in relation to their soil WC, aligned at $19 \%$ in relation to the water-filled pore space (WFPS), indicating the dominating role of gas diffusion. This interpretation was supported by the linear correlation between $V_{d}$ and bulk density. We suggest that the uptake of COS depends on the diffusivity dominated by WFPS, a parameter depending on soil WC, soil structure and porosity of the soil.
\end{abstract}

\section{Introduction}

Among all sulfur trace gases, carbonyl sulfide (COS) is recognized as one of the most abundant volatile sulfur compounds in the atmosphere with an average global concentration of approximately $500 \mathrm{ppt}$ (Barnes et al., 1994; Kjellström, 1998). Because it is nearly inert to photochemical decomposition in the troposphere, most of it is transported into the stratosphere where it undergoes photo dissociation as well as oxidation with $\mathrm{O}\left({ }^{3} \mathrm{P}\right)$ atoms and $\mathrm{OH}$ radicals (Crutzen, 1976; Chin and Davis, 1995). The reaction

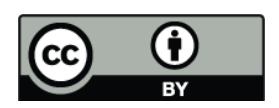

Correspondence to: J. Kesselmeier (jks@mpch-mainz.mpg.de) products are eventually oxidized to sulfuric acid, which then condenses to form aerosol particles.

According to Watts (2000) and Kettle et al. (2002) total global sources and sinks can be regarded as balanced within the uncertainties of the estimates. The global annual source and sink strengths are estimated to be $1.31 \pm 0.25 \mathrm{Tg} \mathrm{a}^{-1}$ and $1.66 \pm 0.79 \mathrm{Tg} \mathrm{a}^{-1}$, respectively (Watts, 2000). However, recent investigations by Sandoval-Soto et al. (2005) reveal that current estimates for the uptake of COS by vegetation seem to be underestimated and indicate that the global atmospheric budget of COS may be considered as unbalanced again.

Known natural sources of COS are oceans (Ferek and Andreae, 1984; Belviso et al., 1986; Johnson and Harrison, 1986), volcanism (Cadle, 1980; Khalil and Rasmussen, 1984; Belviso et al., 1986), precipitation (Mu et al., 2004) and marshes (Aneja et al., 1979; Steudler and Peterson, 1984) as well as anthropogenic sources such as biomass burning, coal-fired power plants, sulfur recovery, chemical processing and $\mathrm{CS}_{2}$ conversion (Khalil and Rasmussen, 1984; Crutzen et al., 1985; Bandy et al., 1993; Watts, 2000; Sturges et al., 2001). Besides photolysis and the reactions with $\mathrm{OH}$ and $\mathrm{O}$ in the stratosphere, vegetation and soils are regarded as the dominating terrestrial sinks (Brown and Bell, 1986; Goldan et al., 1988; Kettle et al., 2002; Sandoval-Soto et al., 2005; Chin and Davis, 1993; Kesselmeier et al., 1999). On the other hand, COS has also a chemical sink in the troposphere through reaction with $\mathrm{OH}$ (Chin and Davis, 1995; Kjellström, 1998). These sinks and sources could drive the seasonality in the Northern (NH) and Southern (SH) Hemispheres with vegetation being the dominant sink factor in the $\mathrm{NH}$ and the oceans the dominant source in the SH (Montzka et al., 2007), but it still remains uncertain.

Since the clarifying work of Castro and Galloway (1991) which demonstrated the sink quality of soils, several publications have given convincing evidence that soils generally act rather as a sink than as a source for COS (Kesselmeier et al., 1999; Kuhn et al., 1999; Geng and Mu, 2004; Steinbacher et

Published by Copernicus Publications on behalf of the European Geosciences Union. 
al., 2004). This implied an obviously better balanced global budget of sinks and sources (Andreae and Crutzen, 1997). One of the main controlling parameters for soil atmosphere exchange is the ambient trace gas concentrations which influences the direction as well as the magnitude of the COS flux between soils and the atmosphere. The net exchange within a certain biotic system is interpreted as the result of simultaneously operating production and consumption processes. This implies the existence of the so-called compensation point, which reflects an ambient concentration where the consumption balances production and the net flux is zero (Lehmann and Conrad, 1996; Kesselmeier et al., 1999; Simmons et al., 1999; Conrad and Meuser, 2000).

In a laboratory study, Kesselmeier et al. (1999) demonstrated that in addition to the linear correlation with atmospheric concentrations, temperature and soil water content (WC) are controlling variables in the COS soil atmosphere flux. To confirm these measurements, we investigated the German arable soil used in the Kesselmeier study again in comparison with two other arable soils from an arid region in the temperate zone of Northeast China, a Finnish soil with a moraine origin, and a podzolic forest soil from Central Siberia. All soils were measured under the same controlled conditions in order to get information about the influence of environmental parameters relating to the control of deposition rates by soil structure and porosity, such as soil WC and water filled pore space (WFPS).

\section{Material and methods}

\subsection{Soil samples}

Soil samples were obtained from four sites: (1) an arable soil from Germany, consisting of sandy clay with low loess content $\left(49^{\circ} 57^{\prime} \mathrm{N}, 8^{\circ} 15^{\prime} \mathrm{E}\right)$; (2) a sandy arable soil from an arid region in the temperate zone in the Northeast of China $\left(45^{\circ} 36^{\prime} \mathrm{N}, 123^{\circ} 21^{\prime} \mathrm{E}\right)$; (3) an arable sandy soil of moraine origin from Finland $\left(61^{\circ} 50^{\prime} \mathrm{N}, 24^{\circ} 20^{\prime} \mathrm{E}\right)$ and (4) a sandy soil from a boreal forest region in Central Siberia $\left(60^{\circ} \mathrm{N}\right.$, $89^{\circ} \mathrm{E}$ ). Samples were taken from the top $5 \mathrm{~cm}$ from multiple grabs (up to 10) at all sites in order to eliminate variability within a single location on the site, and were sieved with a stainless steel sieve with a mesh size of $2 \mathrm{~mm}$. We tried to use the same method to collect all soil samples. But we cannot exclude the variability over time. Samples were stored in polyethylene bags at $5^{\circ} \mathrm{C}$ until analyzed. Carbon, sulfur and nitrogen content, potential water storing capacity (WC), bulk density, WFPS, and $\mathrm{pH}$ at $25^{\circ} \mathrm{C}$ were determined and the results are presented in Table 1. Soil characteristics were determined with a Vario Micro cube analyzer (Elementar Analysensysteme GmbH Hanau, Germany) at the University of Mainz in the laboratory of Micro-analytics. Only $800 \mathrm{mg}$ of soil sample was necessary to analyze the carbon, nitrogen and sulfur content of the soil. The potential wa- ter storing capacity (optimum soil water content; \% of dry weight) was determined according to conventional methods. Soil WC was determined by air-drying and by moistening with deionized water $(R>18 \mathrm{M} \Omega \mathrm{cm})$. WFPS was calculated according to the general particle density $\left(\rho_{S}\right)$, considered to be $2.65 \mathrm{~g} \mathrm{~cm}^{-3}$ for non-organic soils, and the bulk density $\left(\rho_{b}\right)$ (Hillel, 1980). In contrast to the mean general particle density, which is typically taken as a constant for nonorganic soils, the bulk density is highly labile. It is affected by the structure of the soil, that is, its looseness or degree of compaction, as well as by its swelling and shrinkage characteristics. Therefore bulk density was separately measured for each soil type. With this information we were able to calculate the number of pores (Hillel, 1980):

$f$ (\#pores) $=\left[\left(1-\frac{\rho_{b}}{\rho_{S}}\right) \cdot 100\right]$

Using the WC and $f$ (\# pores) for each soil, the WFPS can be obtained according to Eq. (2):

WFPS $(\%)=(\mathrm{WC} / f) \cdot 100$

\subsection{Experimental set-up}

All measurements were performed inside a climatic chamber. Each soil sample $(80 \mathrm{~g})$ was wetted up to its maximum soil WC (Table 1) and incubated in the cuvette system where it dried out in the course of the measurements under COS fumigation with. All experiments were carried out at an ambient concentration $\left(c_{\mathrm{ref}}\right)$ of approximately $1100 \mathrm{ppt}$ to ensure measurable uptake rates at low activities during wet and dry conditions. Air samples were taken at the cuvette outlets every $15 \mathrm{~min}$ and analyzed. Uptake rates were calculated based on the difference between the reference and the sample cuvette. The gas uptake rate $(F)$ was calculated according to Eq. (3) from the measured concentration difference ( $\Delta c=c_{\text {sample }}-c_{\text {ref }}$ ), the chamber flush rate $(Q)$ and the soil dry weight $(d w)$ (Sandoval-Soto et al., 2005).

$F=\Delta c \cdot \frac{Q}{d w}$

As shown by Kesselmeier et al. (1999) it is possible to normalize the COS fluxes because of the existence of a linear correlation between COS concentration and COS uptake. Thus, effects of fluctuations of COS mixing ratios in course of the measurement series were eliminated by normalizing our data to a constant and comparable atmospheric concentration by the calculation of deposition velocities $\left(V_{d}\right)$ in relation to soil $\mathrm{WC}$, as $V_{d}$ is representing the relation between trace gas flux and concentration.

\subsection{Construction and performance of soil enclosures}

The measurements were performed with two dynamic enclosures (cuvettes) made of Teflon (FEP) film (Kesselmeier et al., 1999): one which enclosed the soil sample (200 g or $80 \mathrm{~g}$ ) 
Table 1. Soil chemical and physical characteristics.

\begin{tabular}{lcccc}
\hline Properties & German soil & Chinese soil & Finnish soil & Siberian soil \\
\hline Site description & $\begin{array}{c}\text { Arable sandy } \\
\text { loess content }\end{array}$ & $\begin{array}{c}\text { Arable sandy } \\
\text { boreal }\end{array}$ & $\begin{array}{c}\text { Arable Moraine } \\
\text { origin boreal }\end{array}$ & $\begin{array}{c}\text { Boreal forest } \\
\text { sandy podzolic }\end{array}$ \\
\hline$C_{\text {total }}, \mathrm{wt} \%$ & 2.22 & 0.40 & 2.30 & 0.38 \\
$S_{\text {total }}, \mathrm{wt} \%$ & 0.022 & 0.030 & 0.06 & 0.03 \\
$N_{\text {total }}, \mathrm{wt} \%$ & 0.156 & 0.040 & 0.15 & 0.03 \\
Max Soil WC, \% H $\mathrm{O} \mathrm{g}^{-1} \mathrm{DW}$ & 52.0 & 32.7 & 42.7 & 29.3 \\
Bulk density, g cm & -3 & 1.40 & 1.08 & 1.43 \\
Calculated WFPS, \% & 1.60 & 69.3 & 72.1 & 63.6 \\
pH at $25^{\circ} \mathrm{C}$ & 124.9 & 7.28 & 7.83 & 4.20 \\
\hline
\end{tabular}

and the other serving as an empty reference. Both cuvettes were incubated inside a climate chamber and kept under controlled temperature conditions (between 10 and $40^{\circ} \mathrm{C}$ ). Each of them was flushed with a total ambient airflow of $2 \mathrm{~L} \mathrm{~min}{ }^{-1}$. All tubing coming from the cuvettes was heated up to $30^{\circ} \mathrm{C}$ to prevent water vapor condensation. Temperatures were measured with thermocouples $\left(0.005^{\prime \prime}\right.$, ChromConstantan, Omega, UK). Compressed air was purified by passing it through a multistage gas purification system consisting of three $3 \mathrm{~L}$ columns filled with (1) silicagel with a humidity indicator to remove the water $(1-4 \mathrm{~mm}$, VWR International, Darmstadt, Germany); (2) molecular sieve ( $0.5 \mathrm{~nm}$, VWR International, Darmstadt, Germany) which acted as a drying agent and also filtered out trace gases and radicals like ozone; and (3) charcoal (1-3 mm, Carl Roth) to remove COS. The desired COS mixing ratios were obtained by mixing the purified compressed air with known gas mixtures produced from a permeation device (Haunold, Germany) with COS permeation tubes (VICI Metronics, USA). Mass flow controllers (MKS, USA) were used to regulate all gas flows.

\subsection{Analysis of carbonyl sulfide (COS)}

The uptake of COS was measured with an automated analytical SUlphur Gas AnalyzeR (SUGAR; more detailed information in von Hobe (2000) and von Hobe et al. (2008)) which performed an analysis every $15 \mathrm{~min}$. COS was fully automatically sampled by cryogenic trapping and analyzed with a gas chromatograph equipped with a flame photometric detector. Data were processed and stored with a GC analysis software program (ELAB, OMS Tech, USA).

\subsection{Mathematical best fit}

The mathematical equation developed by Meixner and Yang (2006) gave the best fit to describe the COS exchange dependence on soil WC and WFPS. This mathematical equation was developed for the exchange of NO between soil and the atmosphere, thus taking the same matrix which takes the same biological and physical background into account.
The net COS flux, $F_{\mathrm{COS}}$ is described by $F_{\mathrm{COS}}(\mathrm{WC})=a \mathrm{WC}^{b} \exp (-c \mathrm{WC})$. The parameters $a, b$ and $c$ are related to observed values by

$$
\begin{aligned}
a= & F_{\mathrm{COS}}\left(\mathrm{WC}_{\mathrm{opt}}\right) /\left[\mathrm{WC}_{\mathrm{opt}}^{b} \exp (-b)\right] \\
b= & \ln \left[F_{\mathrm{COS}}\left(\mathrm{WC}_{\mathrm{opt}}\right) / F_{\mathrm{COS}}\left(\mathrm{WC}_{\mathrm{upp}}\right)\right] / \\
& {\left[\ln \left(\mathrm{WC}_{\mathrm{opt}} / \mathrm{WC}_{\mathrm{upp}}\right)+\mathrm{WC}_{\mathrm{upp}} / \mathrm{WC}_{\mathrm{opt}}-1\right] } \\
c= & -b / \mathrm{WC}_{\mathrm{opt}}
\end{aligned}
$$

Thus, the COS exchange at a given temperature was described as a function of $\mathrm{WC}_{\mathrm{opt}}$, this is the soil WC at which the maximum deposition velocity $\left(V_{d}\right)$ is observed, and as a function of $\mathrm{WC}_{\mathrm{upp}}$, this is the soil $\mathrm{WC}$ at which $V_{d}(\mathrm{WC})=V_{d}\left(\mathrm{WC}_{\text {upp }}\right) \approx 0$ for $\mathrm{WC}>\mathrm{WC}_{\text {opt }}$ (Meixner and Yang, 2006). The mathematical fit described the overall behavior reasonably well, but sometimes failed to accurately take the maximum $V_{d}$ into account. Nevertheless, this data point was considered in the discussion because it represented the mean value of at least five measurements.

\section{Results}

Four different soils from around the world were investigated for their exchange of COS with the atmosphere. A first series of measurements was performed with soil from the same German site as investigated by Kesselmeier et al. (1999) and under the same experimental conditions as described therein in order to check the reproducibility after 6 years. These measurements using $200 \mathrm{~g}$ soil, showed maximum uptake rates which were roughly a factor of 4 higher than those from 1999, but with optimal uptake rates at similar soil WC (between 9 and $14 \%$ soil WC) for all temperature ranges investigated (Fig. 1a). The higher uptake rates seem to be the result of unknown effects, but we may take three possible explanations into account: (a) Kesselmeier et al. (1999) measured the uptake rates at a fixed soil WC by measuring at a relative humidity of $90 \%$. Our data was obtained by drying out the soil 

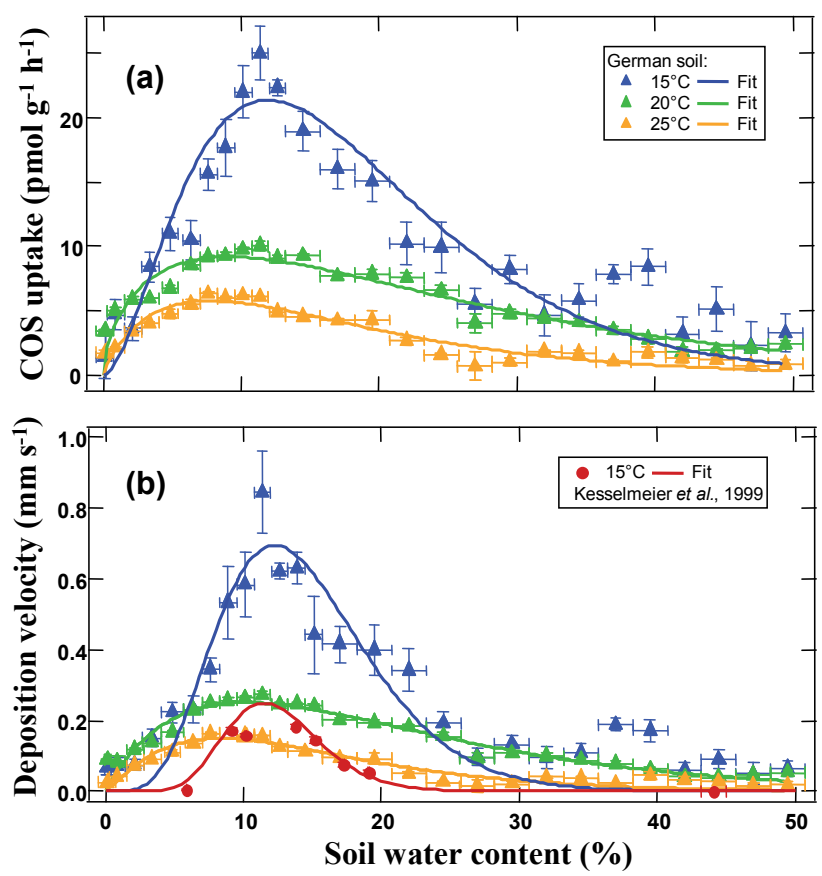

Fig. 1. German arable soil: (a) COS uptake rates $\left(\mathrm{pmol} \mathrm{g}^{-1} \mathrm{~h}^{-1}\right)$ in relation to the soil $\mathrm{WC}(\%)$ at $15^{\circ} \mathrm{C}, 20^{\circ} \mathrm{C}$ and $25^{\circ} \mathrm{C}$ for $200 \mathrm{~g}$ of soil per cuvette. (b) Deposition velocities $\left(V_{d} ; \mathrm{mm} \mathrm{s}^{-1}\right.$; normalized uptake rates) in relation to soil $\mathrm{WC}(\%)$ at $15^{\circ} \mathrm{C}, 20^{\circ} \mathrm{C}$ and $25^{\circ} \mathrm{C}$ for $80 \mathrm{~g}$ of soil per cuvette. The recalculated data at $15^{\circ} \mathrm{C}$ for $80 \mathrm{~g}$ of soil from Kesselmeier et al. (1999) was added in order to provide a comparison of the magnitude of the $V_{d} . V_{d}$ at $10^{\circ} \mathrm{C}$ were near zero $\mathrm{mm} \mathrm{s}^{-1}$ at soil WC's and therefore not shown. Each data point represents the mean value of at least 5 measurements with their standard errors (error bars are $\sigma / \sqrt{ } n$ ). Some error bars are smaller than the symbol.

from his maximum soil WC to $0 \%$ of soil WC with a varying humidity at around 40\%; (b) The difference in achieving the data implies also that our data was taken at the moment the soil was already adapted to the cuvette's environment during a long-term measurement. The data of Kesselmeier et al. was achieved during a short-term measurement where the soil had less time to adapt to the cuvette environment; (c) The third reason, which may be the most important one, could be the developmental stage of the soil, i.e. development of soil quality over time. We assume that the soil microbiological community has changed over the years because of different crops and the use of different fertilizers, which can both influence the microbiological growth in the soil. Such a development represents a general problem for determination of trace gas exchange. Future simultaneous determination of the microbial activity in terms of carbonic anhydrase activity may help to overcome or gradually reduce this problem. If we find a positive relationship between CA activity and gas exchanges, it will be of great help to predict the soil uptake on a regional and global scale. Nevertheless, the well matching optimum for the dependence on WC and the very similar temperature dependence (see below) demonstrate the principal of reproducibility for such measurements.

The uptake rates were shown to correlate linearly with the amount of soil dry weight incubated up to a value where the gas exchange is limited in deeper parts of the soil sample. Kesselmeier and Teusch (1999) demonstrated this linearity to exist up to $200 \mathrm{~g}$ in the case of the German soil sample site. As we wanted to compare different soil samples with unknown saturation behavior, we adapted the experimental conditions to lower amounts of soil, i.e. $80 \mathrm{~g}$. This ensures that the entire soil mass contributes to the exchange of COS with the atmosphere. This could be related to other soil masses according to Kesselmeier et al. (1999) who found a linear correlation of COS uptake and soil mass up to $200 \mathrm{~g}$ per cuvette, but shifted to a saturation-like uptake behaviour with increasing soil masses between 200 and $400 \mathrm{~g}$ of soil. The experiments were carried out at an ambient concentration $\left(c_{\mathrm{ref}}\right)$ of approximately $1100 \mathrm{ppt}$ to ensure measurable uptake rates at low activities (i.e. at dry and wet conditions). Kesselmeier et al. (1999) demonstrated that a positive linear correlation exists between COS uptake and the ambient concentration up to these ranges. Furthermore, for all further calculations, deposition velocities ( $V_{d}$ : i.e. a normalized uptake rate) instead of uptake rates were used in order to eliminate the influence of the fluctuations of COS mixing ratios. The uptake rates for the German soil as recalculated are shown in Fig. 1b. Lower and higher soil WCs led to a decrease in uptake. Moreover, optimum $V_{d}$ was found at $15^{\circ} \mathrm{C}$, at lower and higher air temperatures there was a much lower uptake capability of COS by the German arable soil. $V_{d}$ at $10^{\circ} \mathrm{C}$ was near zero $\mathrm{mm} \mathrm{s}^{-1}$ at all soil WC's and is therefore not shown in Figs. 1 and 2a.

It is well known that a variable parameter depending on soil structure and the porosity of the soil dominates soil WC (Meixner and Yang, 2006). Therefore, we investigated the relationship between $V_{d}$ and WFPS, a parameter depending on soil structure, porosity and soil WC. The bulk densities $\left(\rho_{b}\right)$, necessary to calculate the WFPS, were determined for each soil and are given in Table 1.

At the optimum temperature of $15^{\circ} \mathrm{C}$, the $V_{d}$ for the German soil exhibited an optimum uptake rate at around 29\% WFPS (Fig. 2a). Compared with the 6 year old findings of Kesselmeier et al. (1999), maximum $V_{d}$ was found around the same optimum temperature and the same optimum WFPS. This clearly demonstrates the reproducibility of such measurement techniques as well as the constant characteristics of the soil, although the soil was used annually for agriculture proposes and tilled by the farmers. 


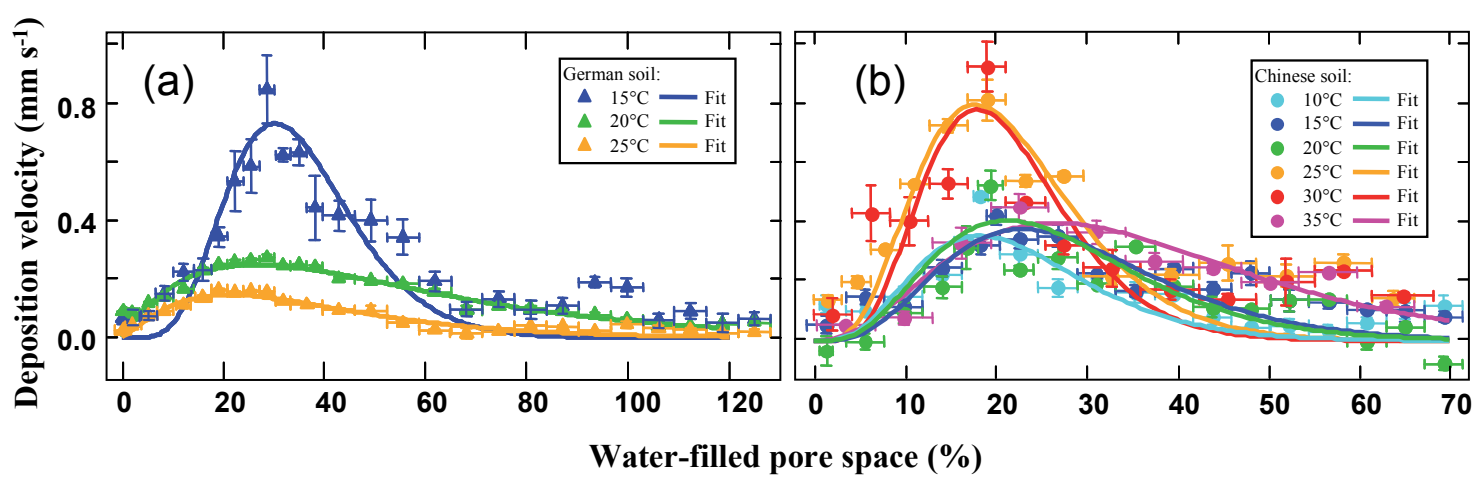

Fig. 2. Deposition velocities $\left(V_{d} ; \mathrm{mm} \mathrm{s}^{-1}\right.$; normalized uptake rates) in relation to WFPS (\%) for (a) the German arable soil at $15^{\circ} \mathrm{C}, 20^{\circ} \mathrm{C}$ and $25^{\circ} \mathrm{C}$ and for (b) the Chinese sandy soil at $10^{\circ} \mathrm{C}, 15^{\circ} \mathrm{C}, 20^{\circ} \mathrm{C}, 25^{\circ} \mathrm{C}, 30^{\circ} \mathrm{C}$ and $35^{\circ} \mathrm{C}$. Each data point represents the mean value of at least 3 measurements with their standard errors (error bars are $\sigma / \sqrt{ } n$ ).

\subsection{Comparison with three boreal soils}

The Chinese soil, a sandy arable soil from an arid region in the temperate zone of Northeast China, had a totally different structure and therefore a much lower maximum soil WC $(32.7 \%)$. Furthermore, calculated $V_{d}$ for this soil exhibited a clear and sharp optimum at lower soil WC $(9 \%)$ and at a much higher optimum temperature $\left(30^{\circ} \mathrm{C}\right) . V_{d}$ related to the WFPS showed a maximum around 19\% WFPS (Fig. 2b).

The uptake capability of an arable Finnish soil exhibited a temperature optimum in the range of $25-30^{\circ} \mathrm{C}$. In the range of 15 to $40 \%$ WFPS, deposition velocities for the Finnish soil are higher than those for the other soils. Plotting $V_{d}$ for the Finnish soil as a function of WFPS demonstrates the importance of soil structure for COS uptake by soils (Fig. 3a). Comparison of the optima of the $V_{d}$ of the Chinese and Finnish soil at their optimum temperature (in the range of $25-30^{\circ} \mathrm{C}$ ) clearly showed optimum $V_{d}$ at around the same WFPS (Fig. 3b). This result indicates that soil structure and physical gas diffusion play an important and dominating role for the uptake of COS by soil.

The above described results were supported by investigations of the Siberian soil from a boreal forest. This soil had a rather acidic $\mathrm{pH}$ compared to the other soils which had a neutral $\mathrm{pH}$ (Table 1) and might therefore have exhibited a distinct behavior. This boreal soil reached the highest $V_{d}$ at temperatures between 25 and $30^{\circ} \mathrm{C}$, a soil WC around $9 \%$ and at a WFPS around 19\% (Fig. 3c). Although this soil originated from a forest instead of an agricultural site, it exhibited a comparable uptake pattern as the German, Chinese and Finnish soil. Furthermore, by comparing the almost identical uptake pattern of the Siberian and Chinese soil (Fig. 3d) we can eliminate the possible influence of the soil $\mathrm{pH}$ within the acidic to neutral range.

\section{Discussion}

The experimental results obtained in this study have confirmed, in agreement with others, that soil is a sink for COS (Castro and Galloway, 1991; Kesselmeier et al., 1999; Kuhn et al., 1999; Geng and Mu, 2004; Steinbacher et al., 2004). The close accordance of our work with the 6 year old findings of Kesselmeier et al. (1999) on the same German arable soil from the same site demonstrated the reproducibility of such measurement techniques as well as the constant characteristics of soils. For both investigations, COS deposition velocities showed a maximum around $11.5 \%$ soil WC, $29 \%$ WFPS and the temperature optimum was found to be around $15^{\circ} \mathrm{C}$. This gave us strong motivation to execute further experiments in order to compare such parameters of the uptake of COS by different soils from different locations in the world.

To our knowledge, this is the first time that four totally different soil types have been parameterized by direct comparison. Earlier models (Kettle et al., 2002) used such data already but the modelling was only based on the measurements of the one soil type and interpolated on a global scale. Our measurements now should guide to a more realistic approach on the COS uptake by soils on a global scale. These four different soils show a distinct behavior in relation to temperature and the soil WFPS, the latter being the dominant factor. This assumes that diffusivity plays a major role in the exchange of COS between soils and the atmosphere. Furthermore, different COS uptake optima related to the soil WC for different analyzed boreal soil types (Chinese, Finnish and Siberian soil) disappeared when the uptake was related to the WFPS. Deposition velocity representing concentration normalized uptake rates exhibited a comparable uptake pattern. The corresponding optima at 19\% WFPS suggests a highly dominating regulating role of gas diffusion/transport in the soil. 


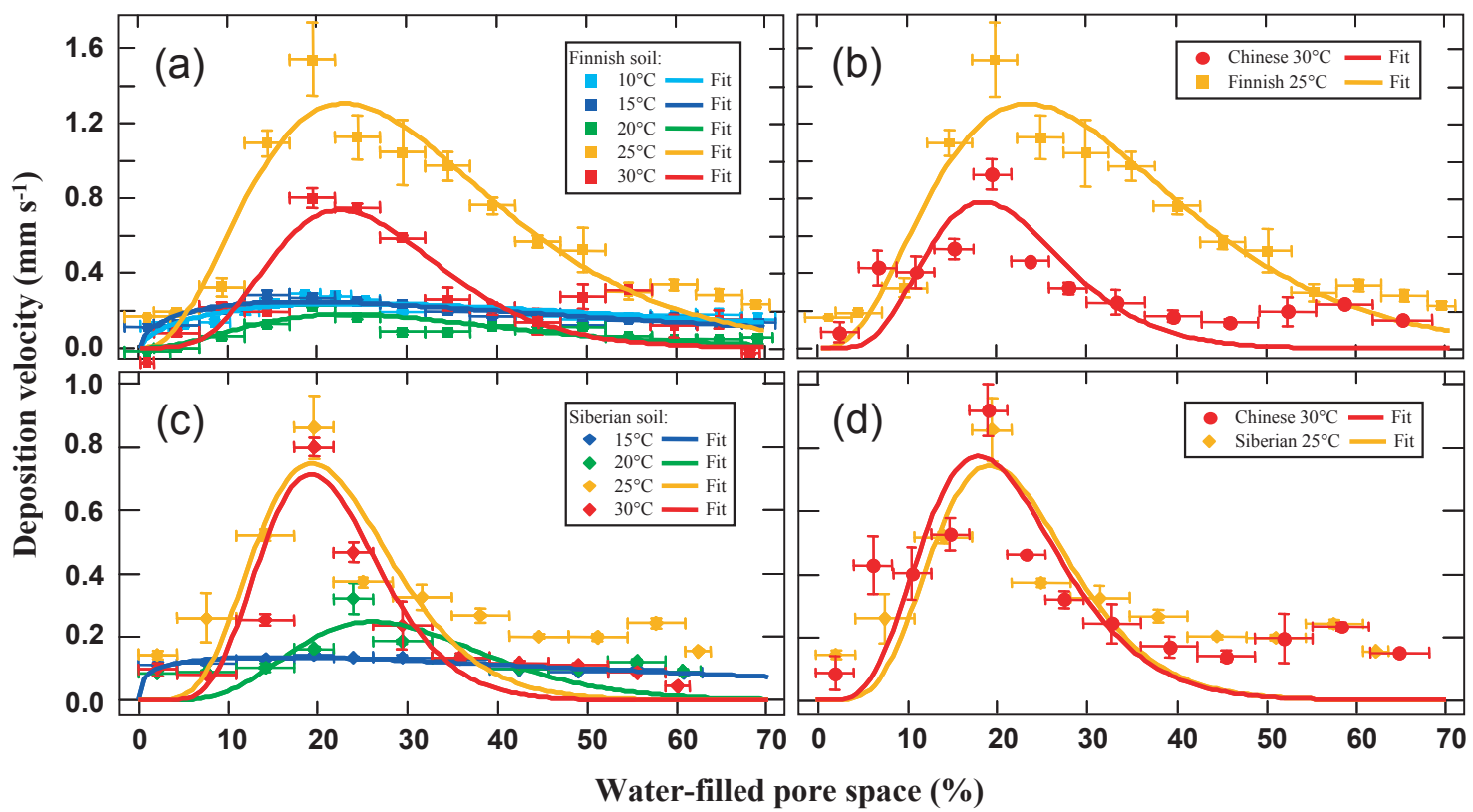

Fig. 3. Deposition velocities $\left(V_{d} ; \mathrm{mm} \mathrm{s}^{-1}\right.$; normalized uptake rates) in relation to WFPS (\%) for (a) the Finnish soil at $10^{\circ} \mathrm{C}, 15^{\circ} \mathrm{C}, 20^{\circ} \mathrm{C}$, $25^{\circ} \mathrm{C}$, and $30^{\circ} \mathrm{C}$ and for (c) the Siberian forest soil between $15^{\circ} \mathrm{C}$ and $30^{\circ} \mathrm{C}$. For both soils an optimum exchange was reached near $19 \%$ WFPS. (b) $V_{d}\left(\mathrm{~mm} \mathrm{~s}^{-1}\right)$ optima for the Finnish and Chinese soil and (d) $V_{d}\left(\mathrm{~mm} \mathrm{~s}^{-1}\right)$ optima for the Siberian and Chinese soil coincide near 19\% WFPS at optimum temperatures. Some error bars are smaller than the symbol $(n \geq 3$; error bars are $\sigma / \sqrt{ } n)$.

Table 2. An overview of the optimum $V_{d}$, optimum temperature, optimum soil WC and WFPS is given for the German, Chinese, Finnish and Siberian soils.

\begin{tabular}{lcccc}
\hline & German soil & Chinese soil & Finnish soil & Siberian soil \\
\hline$V_{d}$ at optimum soil WC and & $0.84 \pm 0.25$ & $0.93 \pm 0.08$ & $1.54 \pm 0.19$ & $0.87 \pm 0.10$ \\
temperature \pm standard error & & & & \\
{$\left[\mathrm{mm} \mathrm{s}^{-1}\right.$ ] } & 15 & 30 & 25 & 25 \\
Optimum temperature $\left[{ }^{\circ} \mathrm{C}\right]$ & 11.5 & 9 & 11.5 & 9 \\
Optimum soil WC $[\%]$ & 29 & 19 & 19 & 19 \\
Optimum WFPS $[\%]$ & & & & \\
\hline
\end{tabular}

The comparison of the three boreal soils highlighted the difference of the uptake capacity as indicated by the different COS deposition velocities. The maximum $V_{d}$ for the Finnish soil was twice as high as the maximum $V_{d}$ for the Chinese and Siberian soil, all considered at their optimal conditions. In contrast, its bulk density was remarkably lower than those of the other soils. With a bulk density of only $1.08 \mathrm{~g} \mathrm{~cm}^{-3}$, the Finnish soil is supposed to have a higher porosity and should therefore have the largest average pore size of all investigated soils, which implies a better diffusivity of COS through the soil. Considering the maximum $V_{d}$ at optimum conditions (e.g. temperature, soil WC and WFPS; see Table 2$)$ in relation to the measured bulk density $\left(\rho_{b}\right)$ of each soil shows a convincing linearity (Fig. 4). This implies the importance of bulk density and thus the porosity of the soil.
These results are useful in order to parameterize the COS uptake by soils and to underline the dominant role of diffusivity depending on the bulk density (linear relationship) and the WFPS. Diffusivity as a limiting factor for COS uptake by soils may play a more important role than previously thought.

Temperature has a significant influence on several biological and biochemical processes, it affects microbial activity and has been used in several laboratory studies to parameterize COS fluxes (Kesselmeier et al., 1999; Steinbacher et al., 2004). The temperature optimum for COS uptake can be understood to depend on enzymatically catalyzed processes, during which the enzymes amplify the trace gas exchange up to a certain threshold temperature. Above this temperature, the enzymes deteriorate and their activity decreases. In this study, measurements of COS uptake for all soils were 


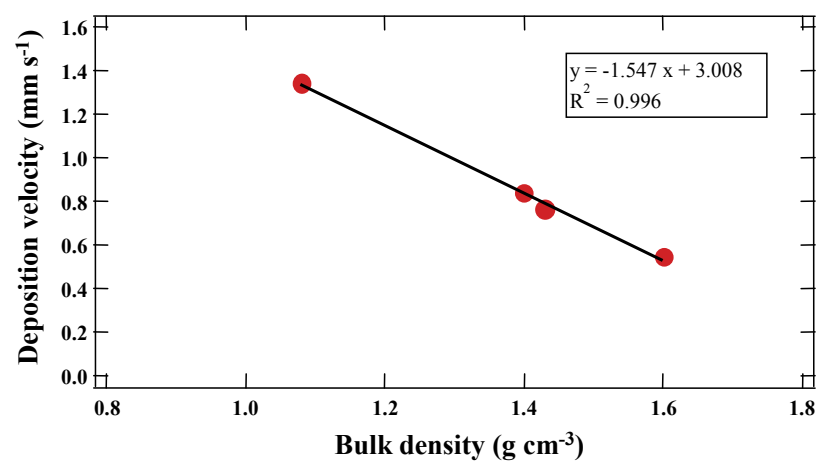

Fig. 4. Maximum $V_{d}\left(\mathrm{~mm} \mathrm{~s}^{-1}\right)$ of all soils at optimum conditions (optimum temperature, optimum soil WC) in relation to the measured bulk density $\left(\mathrm{g} \mathrm{cm}^{-3}\right)$. From left to the right, data points are the maximum $V_{d}$ of the Finnish, Chinese, Siberian and the German soil.

performed at temperatures between 10 and $35^{\circ} \mathrm{C}$. Figure 5 shows the $V_{d}\left(\mathrm{~mm} \mathrm{~s}^{-1}\right)$ for the German, Chinese, Finnish and Siberian soil in relation to incubation temperatures between 10 and $35^{\circ} \mathrm{C}$. All four soils followed a similar uptake pattern. The uptake increased with temperature up to an optimal range, followed by a sharp decrease at higher temperatures.

In contrast to the German soil, originating from a more temperate climate, the boreal soils reached a maximum deposition velocity at surprisingly high temperatures between 25 and $30^{\circ} \mathrm{C}$. The optimum temperature in the case of the German soil was found at around $15^{\circ} \mathrm{C}$ which is in close agreement with the earlier findings of Kesselmeier et al. (1999). We have no explanation, but we may speculate. We expect that the range of uptake rates is depending on the microbial populations. We assume that the micro-organisms of the boreal soils (Chinese, Finnish and Siberian soil) are adapted to more extreme temperature ranges and thus will be active at higher temperatures. The German soil belongs to a temperate zone, where temperatures are not varying so extremely over the year. Thus the results may be discussed as an adaptation of the boreal soils to higher temperatures.

The behavior of exchange processes exhibiting temperature optima as well as dependence on humid conditions clearly supports the influence of a biological process. The enzymatically based COS uptake is quite well understood (Protoschill-Krebs and Kesselmeier, 1992; Protoschill-Krebs et al., 1996; Haritos and Dojchinov, 2005). Carbonic anhydrase (CA) has been identified as the controlling enzyme for COS uptake in algae, lichens, higher plants and soil (Protoschill-Krebs et al., 1996; Kesselmeier et al., 1999; Blezinger et al., 2000; Kuhn and Kesselmeier, 2000). However, as we have learned more about the role of diffusivity dominated by WFPS and bulk density from our studies, there is a need to investigate more soil types in order to allow modeling of soil atmosphere exchange of COS on a global scale. Furthermore, the question how much of the uptake ca-

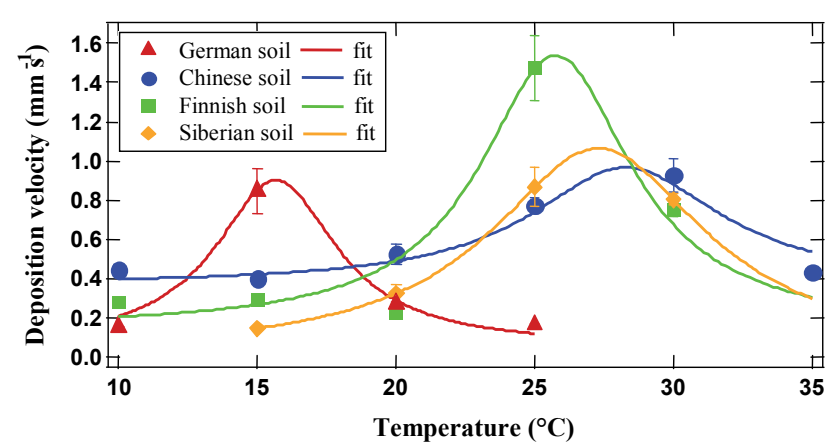

Fig. 5. Normalized deposition velocity data $\left(V_{d} ; \mathrm{mm} \mathrm{s}^{-1}\right)$ for the German, Chinese, Finnish and Siberian soil in relation to incubation temperatures between 10 and $35^{\circ} \mathrm{C}$. All data are given for their optimal soil WC. Some error bars were smaller than the symbol $(n \geq 3$; error bars are $\sigma / \sqrt{ } n$ ). The plotted line represents the mathematical approximation (Meixner and Yang, 2006).

pacity of soils is based on biological (enzymatic) consumption needs to be investigated. As shown by Kesselmeier et al. (1999) an inhibition of the carbonic anhydrase resulted in only $50 \%$ inhibition of COS uptake. It remains unsolved whether non-inhibited enzymes or non-enzymatic decomposition can explain this gap. Further studies needed are determinations of the COS uptake in the field which would give a better idea about estimating the sink strength of soils on a regional and global scale. Answers to these question will help to significantly reduce the existing uncertainties about the global COS budget. As this study can not deliver an estimation of sink strength we can only state that all soil types in this investigation were acting as sinks. Taking into account that i) most soils may act as sinks for COS and ii) a potentially strong underestimation of the sink strength of vegetation (Sandoval et al. 2005), we consider an underestimation of known and unknown sources to be responsible for an unbalanced COS budget.

Acknowledgements. This work was made possible by the support of the Max Planck Society and the International Max Planck Research School on Atmospheric Chemistry and Physics, Mainz. We especially thank H. Stenner from Mainz for providing the German soil, J. Yu for bringing the Chinese soil, K. Katrynski for collecting the Siberian soil samples and G. Eerdekens for shipping the Finnish soil to Germany. We thank W. Dindorf from the laboratory of Micro-analytics of the University in Mainz for providing data on soil chemical characteristics. We also gratefully acknowledge the help of T. W. Andreae with the manuscript.

Edited by: A. Neftel 


\section{References}

Andreae, M. O. and Crutzen, P. J.: Atmospheric aerosols: Biogeochemical sources and role in atmospheric chemistry, Science, 276, 1052-1056, 1997

Aneja, V. P., Overton, J. H., Cupitt, L. T., Durham, J. L., and Wilson, W. E.: Direct measurements of emission rates of some atmospheric biogenic sulfur compounds, Tellus, 31, 174-178, 1979.

Bandy, A. R., Thornton, D. C., and Johnson, J. E.: $\mathrm{CS}_{2}$ measurements in the atmosphere of the western North Atlantic and Northwestern South Atlantic Oceans, J. Geophys. Res., 98, 23 44923 457, 1993.

Barnes, I., Becker, K. H., and Patroescu, I.: The tropospheric oxidation of dimethyl sulfide: A new source of carbonyl sulfide, Geophys. Res. Lett., 21(22), 2389-2392, 1994.

Belviso, S., Nguyen, B. C., and Allard, P.: Estimate of carbonyl sulfide (OCS) volcanic source strength deduced from $\mathrm{OCS} / \mathrm{CO}_{2}$ ratios in volcanic gases, Geophys. Res. Lett., 3, 133-136, 1986.

Blezinger, S., Wilhelm, C., and Kesselmeier, J.: Enzymatic consumption of carbonyl sulfide (COS) by marine algae, Biogeochemistry, 48(2), 185-197, 2000.

Brown, K. A. and Bell, J. N. B.: Vegetation: the missing link in the global cycle of OCS, Atmos. Environ., 20, 537-540, 1986.

Cadle, R. D.: A comparison of volcanic and other fluxes of atmospheric trace gas constituents, Rev. Geophys. Space Phys., 18, 746-752, 1980.

Castro, F. and Galloway, J. N.: A comparison of sulfur-free and ambient air enclosure techniques for measuring the exchange of reduced sulfur gases between soils and the atmosphere, J. Geophys. Res., 96, 15 427-15 437, 1991.

Chin, M. and Davis, D. D.: Global sources and sinks of OCS and $\mathrm{CS}_{2}$ and their contribution, Global Biogeochem. Cy., 7, 321337, 1993.

Chin, M. and Davis, D. D.: A reanalysis of OCS as a source of stratospheric background sulfur aerosol, J. Geophys. Res., 100(D5), 8993-9005, 1995.

Conrad, R. and Meuser, K.: Soils contain more than one activity consuming carbonyl sulfide, Atmos. Environ., 34, 3635-3639, 2000.

Crutzen, P. J.: The possible importance of CSO for the sulfate layer of the stratosphere, Geophys. Res. Lett., 3, 73-76, 1976.

Crutzen, P. J., Heidt, L. E., and Krasnec, J. P.: Tropospheric chemical composition measurements in Brazil during thedry season, $\mathrm{J}$. Atmos. Chem., 2, 233-256, 1985.

Ferek, R. J. and Andreae, M. O.: Photochemical production of carbonyl sulfide in marine surface waters, Nature, 307, 148-150, 1984.

Geng, C. and Mu, Y.: Carbonyl sulfide and dimethyl sulfide exchange between lawn and the atmosphere, J. Geophys. Res., 109, D12302, doi:10.1029/2003JD004492, 2004.

Goldan, P., Fall, D. R., Kuster, W. C., and Fehsenfeld; F. C.: Uptake of COS by growing vegetation: A major tropospheric sink, J. Geophys. Res., 93, 14 186-14 192, 1988.

Haritos, V. S. and Dojchinov, G.: Carbonic anhydrase metabolism is a key factor in the toxicity of $\mathrm{CO}_{2}$ and $\mathrm{COS}$ but not $\mathrm{CS}_{2}$ toward the flour beetle Tribolium castaneum [Coleoptera: Tenebrionidae], Biochemistry and Physiology, Part C, 140, 139-147, 2005.

Hillel, D.: Introduction to soil physics, San Diego, California, Academic, 9-12, 1980.
Johnson, J. E. and Harrison, H.: Carbonyl Sulfide concentrations in the surface waters and above the Pacific Ocean, J. Geophys. Res., 91, 7883-7888, 1986.

Kesselmeier, J., Teusch, N., and Kuhn, U.: Controlling variables for the uptake of atmospheric carbonyl sulfide by soil, J. Geophys. Res., 104(D9), 11 577-11 584, 1999.

Kettle, A. J., Kuhn, U., von Hobe, M., Kesselmeier, J., and Andreae, M. O.: Global budget of atmospheric carbonyl sulfide: Temporal and spatial variations of the dominant sources and sinks, J. Geophys. Res., 107(D22), 4658-4673, 2002.

Khalil, M. A. K. and Rasmussen, R. A.: Global sources, lifetimes and mass balances of OCS and $\mathrm{CS}_{2}$ in the Earth's atmosphere, Atmos. Environ., 18, 1805-1812, 1984.

Kjellström, E.: A three-dimensional global model study of carbonyl sulfide in the troposphere and the lower stratosphere, J. Atmos. Chem., 29, 151-177, 1998.

Kuhn, U., Ammann, C., Wolf, A., Meixner, F. X., Andreae, M. O., and Kesselmeier, J.: Carbonyl sulfide exchange on an ecosystem scale: soil represents a dominant sink for atmospheric COS, Atmos. Environ., 33, 995-1008, 1999.

Kuhn, U. and Kesselmeier, J.: Environmental variables controlling the uptake of carbonyl sulfide by lichens, J. Geophys. Res., 105, 26783-26 792, 2000.

Lehmann, S. and Conrad, R.: Characteristics of turnover of carbonyl sulfide in four different soils, J. Atmos. Chem., 23, 193207, 1996.

Meixner, F. X. and Yang, W. X.: Biogenic emissions of nitric oxide and nitrous oxide from arid and semi-arid land, Dryland Ecohydrology, edited by: D'Odorico, P. and Porporato, A. printed in the Netherlands, Springer, 2006.

Montzka, S. A., Calvert, P., Hall, B. D., Elkins, J. W., Conway, T. J., Tans, P. P., and Sweeny, C.: On the global distribution, seasonality, and budget of atmospheric carbonyl sulfide (COS) and some similarities to $\mathrm{CO}_{2}$, J. Geophys. Res., 112, D09302, doi:10.1029/2006JD007665, 2007.

Mu, Y., Geng, C., Wang, M., Wu, H., and Zhang, X.: Photochemical production of carbonyl sulfide in precipitation, J. Geophys. Res., 109(D13), 301-307, 2004.

Protoschill-Krebs, G. and Kesselmeier, J.: Enzymatic pathways for the metabolization of carbonyl sulfide (COS) by higher plants, Bot. Acta, 105, 206-212, 1992.

Protoschill-Krebs, W. G. C. and Kesselmeier, J.: Consumption of carbonyl sulfide (COS) by higher plant carbonic anhydrase (CA), Atmos. Environ., 30, 3151-3156, 1996.

Sandoval-Soto, L., Stanimirov, M., von Hobe, M., Schmitt, V., Valdes, J., Wild, A., and Kesselmeier, J.: Global uptake of carbonyl sulfide (COS) by terrestrial vegetation: Estimates corrected by deposition velocities normalized to the uptake of carbon dioxide $\left(\mathrm{CO}_{2}\right)$, Biogeosciences, 2, 125-132, 2005, http://www.biogeosciences.net/2/125/2005/.

Simmons, J. S., Klemedtsson, L., Hultberg, H., and Hines, M. E.:Consumption of atmospheric carbonyl sulfide by coniferous boreal forest soils, J. Geophys. Res., 104(D9), 11 569-11576, 1999.

Steinbacher, M., Bingemer, H. G., and Schmidt, U.: Measurements of the exchange of carbonyl sulfide (OCS) and carbon disulfide $\left(\mathrm{CS}_{2}\right)$ between soil and atmosphere in a spruce forest in central Germany, Atmos. Environ., 38, 6043-6052, 2004.

Steudler, P. A. and Peterson, P. J.: Contribution of gaseous sulphur 
from salt marches to the global sulphur cycle, Nature 311, 455457, 1984.

Sturges, W. T., Penkett, S. A., Barnola, S.-M., Chappellaz, J., Atlas, E. and Stroud, V.: A long-term record of carbonyl sulfide (COS) in two hemispheres from firn air measurements, Geophys. Res. Lett., 28, 4095-4098, 2001.

von Hobe, M.: Ph.D. dissertation, University of East Anglia, Norwich, England, 2005. von Hobe, M., Kuhn, U., Van Diest, H., Sandoval-Soto, L., Kenntner, T., Helleis, F., Yonemura, S., Andreae, M. O., and Kesselmeier, J.: Automated in-situ analysis of volatile sulphur gases using a Sulphur Gas Analyser (SUGAR) based on cryogenic trapping and gas-chromatographic separation, Int. J. Environ. Anal. Chem., 88, 303-315, 2008.

Watts, S. F.: The mass budgets of carbonyl sulfide, dimethyl sulfide, carbon disulfide and hydrogen sulfide, Atmos. Environ., 34, 761779, 2000. 